\title{
PRODUCTION OF ANTIOXIDANTS FOR BIODIESEL FROM STRAW BLACK LIQUOR DEPOLYMERIZATION
}

\author{
JOSÉ PALOMO ${ }^{1}$, SAMUEL MOLES ${ }^{1}$, JESÚS SALAFRANCA², NOEMI GIL-LALAGUNA ${ }^{1}$, \\ ALBERTO GONZALO ${ }^{1} \&$ JOSÉ LUIS SÁNCHEZ ${ }^{1}$ \\ ${ }^{1}$ Thermochemical Processes Research Group, Universidad de Zaragoza, Spain \\ ${ }^{2}$ University Analytical Research Group, Aragon Institute of Engineering Research, \\ Universidad de Zaragoza, Spain
}

\begin{abstract}
Black liquor produced from semi-chemical pulping of barley straw has been depolymerized at different temperatures $\left(250\right.$ to $\left.325^{\circ} \mathrm{C}\right)$, times $(1$ to $3 \mathrm{~h}$ ) and initial solids content in the black liquor ( 7 to $14 \%$ ). The obtained degraded and soluble lignin was then used as biodiesel stabilizer (against oxidation). The depolymerization products have been analyzed by gel permeation chromatography, gas chromatography-mass spectrometry (GC-MS), Fourier-transform infrared spectroscopy (FTIR), and phenolic content was quantified by using the Folin-Ciocalteu method. Regarding the molecular weight distribution, temperature and time have been the most influential factors, especially temperature, which decreased the observed molecular weight. The presence of volatile phenolic compounds has been determined by GC-MS. Temperature was found to be the most influential factor: the higher the temperature, the lower the concentration of volatile phenolics. Regarding the FTIR, the measured spectra hardly change when modifying the experimental conditions. Oxidation stability of biodiesel increased with the reaction temperature applied to black liquor, suggesting that the increase of oxidation stability is not only caused by the volatile phenolic compounds.
\end{abstract}

Keywords: black liquor, lignin, biodiesel, oxidation, additives.

\section{INTRODUCTION}

Straw is a readily available source of cellulosic material for the pulp and paper industry, especially for the boardmaking industry [1]. Black liquor is a byproduct, which contains lignin, hemicellulose and other compounds including the cooking chemicals. The recovery of straw black liquor cannot be accomplished by the same burning process as wood kraft black liquors, mainly due to its silica content which causes high viscosity at low solid concentration and scaling problems in the evaporators and burning chambers [2]. Low density and seasonal production are also other disadvantages that have reduced the use of these materials during the last years in favor of wood pulping [1].

Nevertheless, using fiber sources other than wood is interesting from an environmental point of view, as the use of these materials could lead to a better forest management, and provide a more profitable use of agricultural residues. Specifically, soda semi-chemical pulping is a process that uses no sulfur in the digestion, and can render a pulp with good mechanical properties that can be mixed with secondary (recovered) fiber for cardboard paper production [3], [4].

As an important by-product in any pulping process, black liquor contains a significant fraction of the plant lignin, which is the most abundant source of renewable phenolic compounds in nature. Therefore, depolymerization of the lignin macromolecule can be an alternative to combustion, allowing a valorization of its unique chemical structure. Lignin depolymerization leads to the formation of several products including gases, monomers (monoaromatic compounds), oligomers (polyaromatic compounds), non-converted lignin and condensation products. However, because of its stable and polymeric nature, it is difficult to obtain a single product by depolymerization. 
In this work, depolymerization of the lignin contained in a stream of straw black liquor has been studied aiming at converting it to antioxidant additives for biodiesel. Oxidation stability is among the monitored parameters for its commercialization, being poor oxidative stability one of the major issues to deal with before using biodiesel as a fuel for diesel engines. Hence, the main goal of this work is to evaluate the antioxidant potential of lignin-derived products obtained from black liquor depolymerization, as well as to characterize these products using different analytical techniques.

\section{MATERIALS AND METHODS}

\subsection{Black liquor production}

Black liquor (BL) was obtained from batch cooking barley straw for 3 hours, using a liquid to straw weight ratio of $10: 1$ and a $\mathrm{NaOH}$ weight of $9.5 \%$ over the straw dried weight. Temperature was kept at $98-100^{\circ} \mathrm{C}$ during the whole process. Details of the procedure can be found in the published report by Marín et al. [3]. After the digestion, the solid pulp was filtered and discarded, keeping the resulting black liquor for the depolymerization experiments. After the digestion, BL was further concentrated by evaporating water up to a 15 wt.\% solid content, which includes lignin and ash ( $\mathrm{NaOH}$ among other compounds). This BL was kept in a freezer and, prior to each experiment, was diluted to the desired concentration in distilled water. Table 1 shows the black liquor solid (BLS) characterization.

Table 1: Black liquor solid characterization.

\begin{tabular}{cc|c}
\hline \multicolumn{3}{c}{ Proximate analysis (wt.\%, as received) } \\
\hline Moisture: & $2.1 \pm 0.5$ & EN ISO 18134:2015 \\
Ash: & $34.8 \pm 0.4$ & EN ISO 18122:2015 \\
Volatiles: & $55.2 \pm 0.3$ & EN ISO 18123:2015 \\
Fixed carbon: & 7.9 & By difference \\
\hline \multicolumn{3}{c}{ Ultimate analysis (wt.\%, as received) } \\
\hline $\mathrm{C}:$ & $36.5 \pm 0.4$ & Elemental Analyzer LECO CHN \\
$\mathrm{H}:$ & $5.07 \pm 0.05$ & 628 Series \\
$\mathrm{N}:$ & $0.82 \pm 0.04$ & (by difference) \\
$\mathrm{O}:$ & 22.8 & C2000 IKA bomb calorimeter \\
\hline HHV $(\mathrm{MJ} / \mathrm{kg})$ & $14.2 \pm 0.1$ &
\end{tabular}

\subsection{Black liquor depolymerization and biodiesel oxidation stability testing}

Depolymerization experiments were carried out in a PARR Autoclave reactor, model 4575A. $\mathrm{BL}$ was treated varying the initial solids content in $\mathrm{BL}$ from 7 to $14 \%$, reaction time from 1 to $3 \mathrm{~h}$ and temperature from 250 to $325^{\circ} \mathrm{C}$. NaOH is known to be a catalyst in the lignin depolymerization [5], [6], thus no other catalyst was used as it was already present in the BL. In each experiment, a total mass of $200 \mathrm{~g}$ (water + BLS) was used. Table 2 summarizes the experimental conditions, which correspond to a $2^{\mathrm{k}}$ factorial experimental design, with three replicates of the central point. By analysis of variance (ANOVA), the effect of the three experimental factors (time, temperature and initial BLS content) on several response variables has been analyzed.

After the reaction time, the reactor was cooled by means of a water coil. Once the system reached room temperature, residual pressure inside the reactor was released by collecting the 
gas product in a Tedlar bag for GC-TCD analysis (Agilent 3000 Micro Gas Chromatograph). The gas yield was then calculated using the following data: final pressure in the sealed reactor at room temperature, free reactor volume $(300 \mathrm{~mL})$ and gas volumetric composition. The liquid content in the reactor was poured into a beaker and weighted. The liquid product and the washing solution were filtrated and the insoluble solid residue (ISR) was dried at $100^{\circ} \mathrm{C}$ overnight and weighted. An aliquot of filtrated liquid was dried overnight $\left(40^{\circ} \mathrm{C}\right)$ in order to determine, by weight difference, the amount of soluble degraded lignin (SDL) present in the liquid product. Finally, the product distribution was calculated as the mass yield of each product (gas, ISR and SDL) with respect to initial solid content in the raw black liquor. The soluble degraded lignin was the product to be tested as additive for biodiesel.

Sunflower biodiesel was produced at laboratory scale as previously reported [7]. Neat biodiesel and the liquid products generated from lignin depolymerization were blended at such a proportion that the initial addition of lignin-derived compounds into biodiesel was 3 wt.\%. This blend was distilled under vacuum. Once the water had been removed, the mixture of biodiesel and lignin-derived compounds was magnetically stirred (30 min) and centrifuged (15 min, $4500 \mathrm{rpm}$ ). The insoluble fraction of additive settled to the bottom of the centrifugation tube, while the homogeneous upper phase, composed of biodiesel and soluble compounds, was carefully separated, after which it was considered as the doped sample of biodiesel. Biodiesel oxidation stability was measured with a PetroOXY equipment (Petrotest Instruments $\mathrm{GmbH} \& \mathrm{Co}$. KG) according to the test method described in the EN 16091 standard. The improvement of PetroOXY time (OXY) with respect to the oxidation stability of neat biodiesel involved in each doping process was calculated.

\subsection{Soluble degraded lignin (SDL) characterization}

Gel permeation chromatography (GPC) was used to determine the molecular weight of the SDL. It is a well stablished technique for the determination of the molar mass of polymers (as Mw, Mn or Mp), such as lignin, although it has several drawbacks [8], as the need of derivatize the lignin in order to increase their solubility in organic solvents, which is known to affect the measured $\mathrm{Mw}$ [9]. The use of aqueous GPC is also possible, avoiding the derivatization step [10], [11]. Thus, aqueous phase GPC was chosen after testing the solubility of both lignin and its depolymerization products. A Waters 1515 isocratic pump with a 2414 Refractive Index detector was used, with a Waters Ultrahydrogel pre-column $(6 \times 40 \mathrm{~mm})$ and two Waters Ultrahydrogel $(7.8 \times 300 \mathrm{~mm})$ columns heated at $40^{\circ} \mathrm{C}$. A mixture of $0.004 \% \mathrm{NaOH}, 0.1 \% \mathrm{LiBr}$ and $0.05 \% \mathrm{NaN}_{3}$ (all \% by weight) was used as mobile phase at $0.8 \mathrm{~mL} / \mathrm{min}$. The liquid obtained from the reactor was filtered with a syringe filter $(0.45 \mu \mathrm{m})$ and diluted to $1 \mathrm{~g} / \mathrm{L}$ in the mobile phase prior to injection $(100 \mu \mathrm{L})$. Besides the calculation of $\mathrm{Mn} / \mathrm{Mw}$, some authors have used the collected data to gain insight on the molecular weight distribution by deconvoluting the GPC chromatograms in peaks that can be ascribed to fractions with different $\mathrm{Mw}$ [12], [13]. This approach can be useful to assess the extent of BL depolymerization.

FTIR spectroscopy was also used in order to obtain information of the main SDL functional groups. Samples were dried and the solid measured in a Bruker Alfa FTIR spectrometer by attenuated total reflectance (ATR).

Volatile content of the SLD samples was analyzed by GC/MS using an Agilent 7890A $\mathrm{GC}$ with a $5975 \mathrm{C}$ MS detector. Aqueous samples were filtered $(0.45 \mu \mathrm{m})$ and directly injected $\left(1 \mu \mathrm{L}, 250^{\circ} \mathrm{C}\right)$, using a HP-FFAP column (50 m long, $200 \mu \mathrm{m}$ diameter, $0.3 \mu \mathrm{m}$ film thickness) and a $1 / 50$ split ratio. Initial temperature was $50^{\circ} \mathrm{C}$ for $2 \mathrm{~min}$, then raised at $10^{\circ} \mathrm{C} / \mathrm{min}$ until reaching $235^{\circ} \mathrm{C}$, after what it was held for $21.5 \mathrm{~min}$. Helium ( $99.999 \%$ purity) 
was used as carrier gas at constant flow $(1 \mathrm{~mL} / \mathrm{min})$. Chromatograms were acquired in scan mode (m/z 45-240 Da) and the MS NIST 2014 library was used for peak identification. Guaiacol, one of the most abundant compounds identified, was used as reference for calibration, referring the concentrations to its response. Detection limit was $3.3 \mu \mathrm{g} / \mathrm{g}$.

The Folin-Ciocalteu colorimetric method was also used to characterize the phenolic content of SDL, using gallic acid as calibration standard.

\section{RESULTS}

\subsection{Product distribution}

Table 2 summarizes the results of product distribution calculated as the mass yields of insoluble solid residue (ISR), soluble depolymerized lignin (SDL) and gas product with respect to the initial mass of BLS fed to the reactor (14-28 $\mathrm{g}$ of BLS).

Table 2: Product distribution after lignin depolymerization.

\begin{tabular}{ccccccc}
\hline $\begin{array}{c}\text { Exp. } \\
\text { code \# }\end{array}$ & T $\left({ }^{\circ} \mathrm{C}\right)$ & $\begin{array}{c}\text { Time } \\
(\mathrm{h})\end{array}$ & $\begin{array}{c}\text { BLS content } \\
(\text { wt. } \%)\end{array}$ & $\begin{array}{c}\text { ISR yield } \\
(\text { wt.\%) }\end{array}$ & $\begin{array}{c}\text { SDL yield } \\
(\text { wt.\%) }\end{array}$ & $\begin{array}{c}\text { Gas yield } \\
(\text { wt.\%) }\end{array}$ \\
\hline A1 & 250 & 1 & 7 & 7.0 & 87.0 & 2.9 \\
A2 & 325 & 1 & 7 & 7.1 & 64.4 & 4.9 \\
A3 & 250 & 3 & 7 & 1.3 & 77.6 & 3.6 \\
A4 & 325 & 3 & 7 & 3.56 & 61.0 & 6.3 \\
A5 & 250 & 1 & 14 & 4.3 & 73.5 & 2.5 \\
A6 & 325 & 1 & 14 & 7.8 & 62.8 & 5.5 \\
A7 & 250 & 3 & 14 & 11.6 & 74.7 & 3.4 \\
A8 & 325 & 3 & 14 & 7.0 & 49.0 & 7.5 \\
A9 & 287.5 & 2 & 10.5 & 5.0 & 74.0 & 3.2 \\
A10 & 287.5 & 2 & 10.5 & 5.6 & 68.7 & 3.9 \\
A11 & 287.5 & 2 & 10.5 & 5.7 & 69.2 & 4.8 \\
\hline
\end{tabular}

The ANOVA analysis shows that the ISR yield is significantly influenced by the initial solid concentration: higher solid content leads to higher ISR yield. Although the other factors (temperature and reaction time) have not been shown as significant terms themselves, the relative impact of the initial BLS content depends on the value of these factors (the interactions between all the factors appear as significant terms). Thus, working with the highest initial solid content at lower temperature and for a longer reaction time lead to the greatest formation of insoluble solid (Fig. 1(a)). On the other hand, ISR formation is minimized by operating at the lowest initial BLS content, the lowest temperature and longer reaction time (Fig. 1(b)). All these interactions highlight the complexity of re-polymerization reactions occurring during the process, which should be minimized in order to reduce the loss of carbon in the form of such residual material.

According to the ANOVA analysis, the SDL yield has been found to be negatively affected by the increase of the three operating factors, where temperature was shown to have the strongest effect. Thus, the best conditions for increasing the additive production rate have been found to be the lowest temperature $\left(250^{\circ} \mathrm{C}\right)$, the lowest BLS content $(7 \%)$ and the shortest reaction time $(1 \mathrm{~h})$, which provided a SLD yield as high as $87 \%$. The interaction between the three factors has been found to be a significant term, which means that the impact of each factor depends on the value of the others. 


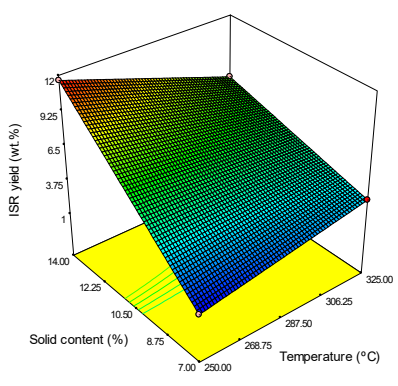

(a)

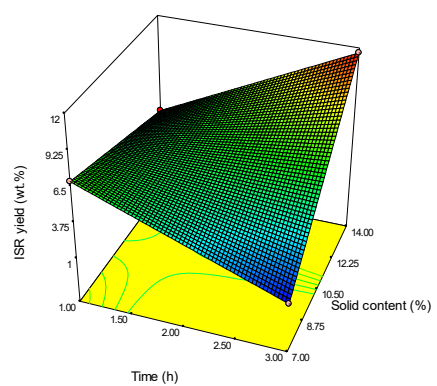

(b)

Figure 1: Effect of operating factors on ISR yield. (a) Reaction time of $3 \mathrm{~h}$; (b) Temperature of $250^{\circ} \mathrm{C}$.

Lastly, the gas yield accounts for $2.5-7.5 \%$ of the initial mass of solid raw material (BLS) and, according to the statistical analysis, is positively affected by temperature and reaction time. These trends agree with the aforementioned discussion: SLD production may be reduced at higher temperature and longer reaction time in favor of gas production. This gas was mainly composed of $\mathrm{CO}_{2}$ (57-90 vol.\%, $\mathrm{N}_{2}$-free basis), $\mathrm{CO}$ (2-9 vol.\%, $\mathrm{N}_{2}$-free basis) and $\mathrm{H}_{2}$ (5-39 vol.\%, $\mathrm{N}_{2}$-free basis). $\mathrm{H}_{2}$ production was clearly enhanced at higher temperature, opposite to $\mathrm{CO}_{2}$ fraction, which was increased at lower temperature.

\subsection{GPC deconvolution}

The obtained curves for both untreated (BLS) and treated black liquor (SDL) visually seem to be composed of several peaks (as shown later) that could be attributed to fractions of different molecular weights. It has been checked that all the GPC peaks can be deconvoluted in several Gaussian curves, with a good fit of the experimental GPC curve (minimum $\mathrm{R}^{2}$ of 0.987). Assuming the same response factor (i.e., different fractions have similar refraction indexes), an analysis on how the depolymerization conditions affect the molecular weight distribution can be carried out.

The GPC profiles of the raw BLS and of a depolymerized sample (A10) are shown in Fig. 2. All the treated samples showed similar peaks. Specifically, seven peaks, which were labelled as P1 to P7, were found in all the treated samples at a similar time. Table 3 summarizes the Mp of the observed peaks in both BLS and a treated sample (central point, A10), together with their area percentage. In the case of A10, the average Mp (calculated at the average time of the 11 samples from the experimental design) and its $95 \%$ confidence interval are presented. Mathematical deconvolution of the curves allowed calculating the area percentage of each of the seven peaks. In the raw BLS, the first peak that was observed (contributing with only $3.9 \%$ of the total area) has a Mp of about $97100 \mathrm{Da}$, and completely disappears in the treated samples. The second peak, which was quite wide and centered at $20900 \mathrm{Da}$, is the most important one in area. The latter decreased after the hydrothermal treatment both in area (from 40.8 to $8.2 \%$ ) and in Mp, appearing with the same shape and with a Mp of $14200 \mathrm{Da}$ in the treated samples. A small peak in the raw BLS appearing at $8100 \mathrm{Da}$ seemed to shift to a slightly higher Mp with a similar importance. The BLS fraction of $2400 \mathrm{Da}$ increased from 6.3 to $15.4 \%$, and also its Mp to $2520 \mathrm{Da}$. The last peak observed in BLS, which was the second by area (31.5\%), increased both in area (to $58.4 \%$ ) and in Mp (from 450 to 530 ). 


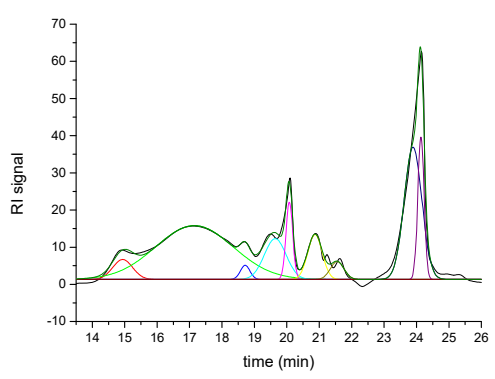

(a)

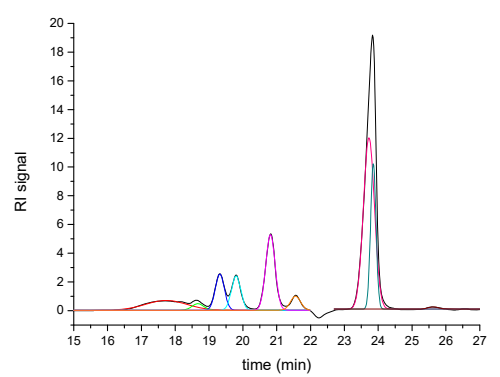

(b)

Figure 2: GPC of (a) Raw BLS; and (b) Soluble degraded lignin (A10 sample).

Table 3: Mp and area percentage of deconvoluted peaks.

\begin{tabular}{cc|cc}
\hline \multicolumn{2}{c|}{ Raw BLS } & \multicolumn{2}{c}{ A10 depolymerized sample } \\
\hline Mp & Area percentage & Average Mp & Area percentage \\
\hline 97100 & 3.9 & - & \\
20900 & 40.8 & $14200 \pm 500(\mathrm{P} 1)$ & 8.2 \\
8100 & 1.3 & $8320 \pm 50(\mathrm{P} 2)$ & 1.6 \\
5080 & 8.7 & $5680 \pm 30(\mathrm{P} 3)$ & 6.8 \\
3640 & 5.1 & $4390 \pm 40(\mathrm{P} 4)$ & 5.8 \\
2400 & 6.3 & $2520 \pm 10(\mathrm{P} 5)$ & 15.4 \\
1990 & Not integrated & - & \\
1620 & 2.4 & $1710 \pm 10(\mathrm{P} 6)$ & 3.3 \\
450 & 31.5 & $530 \pm 10(\mathrm{P} 7)$ & 58.4 \\
\hline
\end{tabular}

Table 4 shows the average molecular weights in number $(\mathrm{Mn})$ and in weight $(\mathrm{Mw})$, as well as the polydispersity index (PI, calculated as the ratio of $\mathrm{Mw}$ to $\mathrm{Mn}$ ) obtained by the GPC analysis.

Table 4: Average molecular weights and polydispersity determined by GPC.

\begin{tabular}{cccccc}
\hline T $\left({ }^{\circ} \mathrm{C}\right)$ & Time (h) & $\begin{array}{c}\text { BLS content } \\
(\text { wt. } \%)\end{array}$ & Mn & Mw & PI \\
\hline 250 & 1 & 7 & 3160 & 10260 & 3.2 \\
325 & 1 & 7 & 2590 & 9350 & 3.6 \\
250 & 3 & 7 & 2960 & 9230 & 3.1 \\
325 & 3 & 7 & 2060 & 6960 & 3.4 \\
250 & 1 & 14 & 3820 & 12390 & 3.2 \\
325 & 1 & 14 & 2130 & 6620 & 3.1 \\
250 & 3 & 14 & 3020 & 10290 & 3.4 \\
325 & 3 & 14 & 1970 & 4990 & 2.5 \\
287.5 & 2 & 10.5 & 3060 & 11040 & 3.6 \\
287.5 & 2 & 10.5 & 2880 & 11020 & 3.8 \\
287.5 & 2 & 10.5 & 2900 & 10330 & 3.6 \\
\hline
\end{tabular}


The ANOVA of the Mn data shows that this parameter decreased when increasing both temperature and reaction time, but it was not affected by the initial concentration of solids. The effect of temperature was roughly double that the effect of time in the tested ranges. A similar trend was observed for Mw, although for this parameter the interaction between time and temperature was statistically significant. Polydispersity was not significantly affected by the experimental conditions, showing a variation from 2.5 to 3.8 .

The analysis of variance (ANOVA) of the areas of the different peaks showed that the highest Mp peak (P1) decreased when temperature and time were increased. On the other hand, the smallest Mp peak (P7) increased, thus showing the effect of the depolymerization conditions.

\subsection{GC/MS analysis and Folin-Ciocalteu phenolic content}

Using GC/MS/FID, 30 different compounds were clearly identified in the hydrotreated liquid samples, of which eleven were phenolic-based compounds:

- The total concentration of the 11 identified phenolic compounds ranged from 530 to $2190 \mu \mathrm{g}$ per $\mathrm{g}$ of treated BL. Only two of them appeared in all the samples: guaiacol (ranging from 80 to $1050 \mu \mathrm{g}$ per g of treated BL) and phenol (from 350 to $450 \mu \mathrm{g}$ per $\mathrm{g}$ of treated BL), and their joint concentration represented from 65 to $97 \%$ of the total content of phenolics. 2-methylbenzenemethanol appeared in 9 samples, but its concentration only ranged from 4.5 to $53.5 \mu \mathrm{g}$ per g of treated BL; 2,6 dimethoxyphenol appeared in 7 samples, and in some of these samples it reached concentrations up to $600 \mu \mathrm{g}$ per $\mathrm{g}$ of treated BL. These four compounds represent 75 to $98 \%$ of the total phenolics concentration in the different samples.

- Ten cyclic compounds were also identified, with only one of them appearing in all the hydrotreated samples (2,3-dimethyl-2-cyclopenten-1-one). Cycloheptanol appeared in 8 depolymerized samples. The maximum concentration for any of these compounds was $40 \mu \mathrm{g}$ per $\mathrm{g}$ of treated BL.

- Four different acids were identified (acetic, butanoic, 4-hidroxybutanoic and pentanoic). Only acetic acid was present in the 11 depolymerized samples, with concentrations ranging from 4.4 to $20.6 \mu \mathrm{g}$ per g of treated BL. Pentanoic acid, the next more abundant, was present in only 3 samples.

- Four aromatic compounds, with a maximum concentration of $50 \mu \mathrm{g}$ per g of treated BL, where 1,2,3-trimethoxy-5-methylbenzene (appearing in 4 samples) was the most abundant.

Table 5 shows the concentration of each chemical family identified by GC/MS and the total yield of volatile phenolics, calculated from the $\mathrm{GC} / \mathrm{MS}$ concentration data and expressed as $\mathrm{mg} / \mathrm{g}$ BLS. The Folin-Ciocalteu $(\mathrm{F}-\mathrm{C})$ method was also used to characterize the phenolic content in SDL, and was measured as $\mathrm{mg}$ of gallic acid equivalent per $\mathrm{g}$ of SDL solid. The ANOVA calculation shows that both the initial BLS content and the temperature ("S" and "T" in equations) affected the concentration of total phenolics detected by GC/MS. Eqn 1 shows the relative influence of the factors, where temperature and BLS content are expressed as coded terms, i.e., they range from -1 for the lowest level $\left(250^{\circ} \mathrm{C}\right.$ and $7 \%$ of BLS, respectively) to $+1\left(325^{\circ} \mathrm{C}\right.$ and $14 \%$ of BLS, respectively)

Total phenolics concentration $(\mu \mathrm{g} / \mathrm{g}$ of treated $\mathrm{BL})=1301-640 \cdot \mathrm{T}+106 \cdot \mathrm{S}$. 
Table 5: Concentration of volatile compounds grouped by chemical families $(\mu \mathrm{g} / \mathrm{g}$ treated $\mathrm{BL}$ ), phenolic content (estimated from the $\mathrm{F}-\mathrm{C}$ method) and yield of volatile phenolics.

\begin{tabular}{|c|c|c|c|c|c|c|c|c|}
\hline $\begin{array}{l}\text { Temp } \\
\left({ }^{\circ} \mathrm{C}\right)\end{array}$ & $\begin{array}{l}\text { Time } \\
\text { (h) }\end{array}$ & $\begin{array}{c}\text { BLS } \\
\text { content } \\
\text { (wt. } \% \text { ) }\end{array}$ & $\begin{array}{c}\text { Acids } \\
(\mu \mathrm{g} / \mathrm{g} \\
\text { treated } \\
\text { BL) }\end{array}$ & $\begin{array}{l}\text { Aromatics } \\
(\mu \mathrm{g} / \mathrm{g} \\
\text { treated } \\
\mathrm{BL})\end{array}$ & $\begin{array}{c}\text { Cyclics } \\
(\mu \mathrm{g} / \mathrm{g} \\
\text { treated } \\
\mathrm{BL})\end{array}$ & $\begin{array}{c}\text { Phenolics } \\
(\mu \mathrm{g} / \mathrm{g} \\
\text { treated } \\
\mathrm{BL})\end{array}$ & $\begin{array}{c}\text { Volatile } \\
\text { phenolics } \\
\text { yield } \\
\text { (mg/g } \\
\text { BLS) } \\
\end{array}$ & $\begin{array}{c}\mathrm{F}-\mathrm{C} \\
(\mathrm{mg} / \mathrm{g} \\
\mathrm{SDL})\end{array}$ \\
\hline 250 & 1 & 7 & 8.2 & 107,4 & 43.3 & 1882.9 & 25.7 & 4.3 \\
\hline 325 & 1 & 7 & 7.4 & 0,0 & 31.1 & 531.1 & 7.2 & 2.0 \\
\hline 250 & 3 & 7 & 5.0 & 28,1 & 12.8 & 1695.7 & 23.0 & 3.6 \\
\hline 325 & 3 & 7 & 24.7 & n.d. & 106.7 & 671.7 & 9.2 & 1.7 \\
\hline 250 & 1 & 14 & 28.2 & 53.8 & 77.6 & 2189.6 & 14.4 & 5.5 \\
\hline 325 & 1 & 14 & 15.4 & 49.1 & 69.9 & 840.5 & 5.4 & 3.2 \\
\hline 250 & 3 & 14 & 38.4 & 92,7 & 85.3 & 1995.4 & 13.0 & 5.5 \\
\hline 325 & 3 & 14 & 25.0 & n.d. & 68.6 & 602.3 & 3.7 & 1.3 \\
\hline 287,5 & 2 & 10.5 & 15.5 & n.d. & 13.5 & 769.7 & 6.9 & 2.7 \\
\hline 287,5 & 2 & 10.5 & 5.8 & 6.0 & 33.1 & 884.7 & 7.9 & 4.6 \\
\hline 287,5 & 2 & 10.5 & 5.3 & 7.1 & 29.7 & 915.7 & 8.3 & 3.8 \\
\hline
\end{tabular}

Temperature exerted a negative influence (the higher the reaction temperature, the lower the phenolics concentration) whereas the BLS content, as it could be expected, exerted a positive effect, that is, the higher the lignin content, more concentration of phenolics were found in the resulting liquid after hydrotreating (Fig. 3). Temperature was the most influencing factor, since its increase from 250 to $325^{\circ} \mathrm{C}$ led to an average decrease of phenolics of $1200 \mu \mathrm{g}$ per $\mathrm{g}$ of treated BL. On the other hand, a change in BLS content from $7 \%$ to $14 \%$ only led to an increase in the phenolic concentration of approximately $200 \mu \mathrm{g}$ per $\mathrm{g}$ of treated BL. Hence, the effect of the initial BLS content was not as strong as the impact of temperature, as doubling the feedstock or source of phenolics (BLS content) did not double the concentration of these compounds derived from lignin.

Fig. 3 also shows that the phenolics concentration at the central point conditions was similar to the one obtained at higher temperature (significant curvature). The ANOVA can be also applied to the measured concentration of the three most abundant compounds (guaiacol, phenol and 2,6 dimetoxy phenol). The ANOVA of the guaiacol concentration shows that only the reaction temperature exerted a significant influence (Fig. 4(a)). As expected, higher temperatures led to a lower production of guaiacol, as shown in eqn (2):

$$
\text { Guaiacol concentration }(\mu \mathrm{g} / \mathrm{g} \text { treated } \mathrm{BL})=551-407 \cdot \mathrm{T} \text {. }
$$

On the other hand, the phenol concentration was not statistically affected by any of the experimental conditions tested, whereas 2,6-dimethoxyphenol concentration decreased with both temperature ("T") and reaction time ("t") and increased with BLS content ("S") (eqn (3); Fig. 4(b)).

\section{2,6-dimethoxyphenol concentration $(\mu \mathrm{g} / \mathrm{g}$ treated $\mathrm{BL})=252-249 \cdot \mathrm{T}-41 \cdot \mathrm{t}+16 \cdot \mathrm{S}+35 \cdot \mathrm{T} \cdot \mathrm{t}$.}

The production of volatile phenolic compounds was also calculated in terms of mass yield with respect to the mass of black liquor solid (mg of phenolics per $\mathrm{g}$ of BLS) (Table 5). According to the ANOVA, both the temperature and the initial BLS content exerted a negative influence on the conversion rate of BLS to volatile phenolics, as shown in eqn (4): 


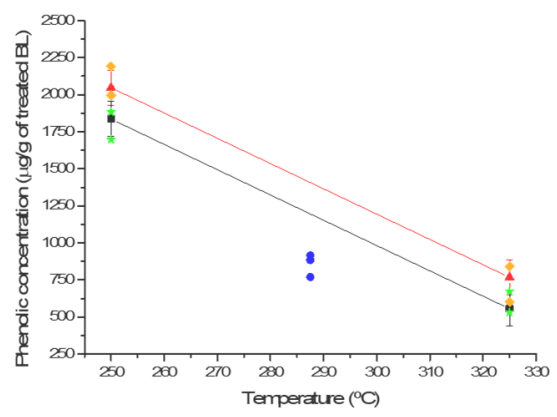

Figure 3: Concentration of phenolic compounds in the treated black liquor (experimental data: $\star 7 \%$ solids, $\diamond 14 \%$ solids, $\bullet$ central points).

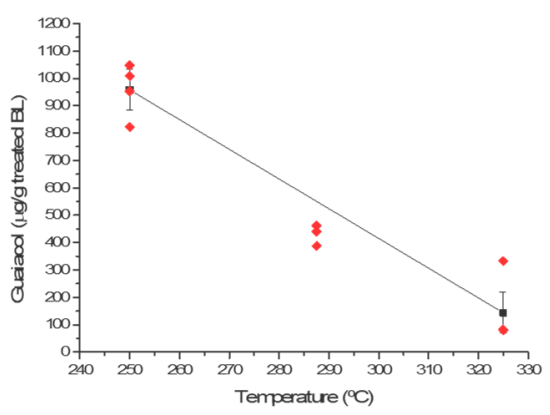

(a)

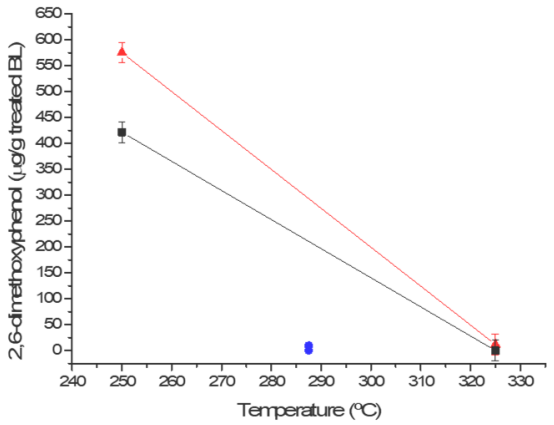

(b)

Figure 4: (a) Concentration of guaiacol ( $\diamond$ experimental points); (b) 2,6-dimethoxyphenol in the treated black liquor $(\boldsymbol{\Delta} 1 \mathrm{~h}$ reaction time, $\boldsymbol{\square} \mathbf{\mathrm { h }}$ reaction time, $\bullet$ central points).

Volatile phenolics yield $(\mathrm{mg} / \mathrm{g}$ BLS $)=12.7-0.3 \cdot \mathrm{T}-4.8 \cdot \mathrm{S}+0.01 \cdot \mathrm{T} \cdot \mathrm{S}$.

On the other hand, the equivalent phenolic content measured by the $\mathrm{F}-\mathrm{C}$ method was only affected by temperature: the higher the temperature, the lower the $\mathrm{F}-\mathrm{C}$ content, ranging from $5.5 \mathrm{mg}$ gallic acid per $\mathrm{g}$ of DSL at $250^{\circ} \mathrm{C}$ to $1.3 \mathrm{mg}$ gallic acid per $\mathrm{g}$ of DSL at $325^{\circ} \mathrm{C}$.

\subsection{FTIR analysis}

As can be seen in Fig. 5, significant differences could be observed among the samples subjected to hydrothermal treatment in comparison to the original BLS. One of the most relevant observation that could be made is the notorious increase in the broad peak (3500-3050 $\mathrm{cm}^{-1}$ ), corresponding to the phenol and alcohol O-H stretching, which are the most abundant compounds.

According to previous studies [14], [15], the peaks in the $2970-2720 \mathrm{~cm}^{-1}$ region are related to $\mathrm{C}-\mathrm{H}$ stretching in alkenes and alkanes; the bands between 1576 and $1542 \mathrm{~cm}^{-1}$ are characteristic of aromatic ring vibrations. Phenolic ring and $\mathrm{O}-\mathrm{H}$ are responsible of the 


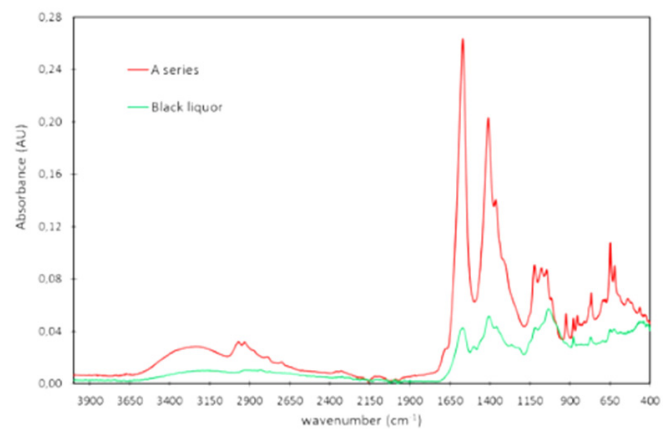

Figure 5: FTIR-ATR spectra of the hydrothermally treated samples (average of all SDL samples) compared to the original BLS.

bands ranging from 1413 to $1337 \mathrm{~cm}^{-1}$, while peaks in the $1121-1088 \mathrm{~cm}^{-1}$ region are due to C-O stretching. Finally, the bands observed at the lowest wavenumbers $\left(923-616 \mathrm{~cm}^{-1}\right)$ correspond to out-of-plane $\mathrm{C}-\mathrm{H}$ bending. In order to get the maximum information, first derivative of spectra was obtained. Six bands were significant from a statistical point of view. The Pearson correlation coefficient was calculated and values higher than 0.850 were considered as relevant. Only a positive correlation (0.927) was found between bands at 1141 and $1610 \mathrm{~cm}^{-1}$, whereas three negative correlations were noticed between bands at 1355 and $1610 \mathrm{~cm}^{-1}(-0.943), 1355$ and $1446 \mathrm{~cm}^{-1}(-0.861)$, and 885 and $887 \mathrm{~cm}^{-1}(-0.970)$. In any case, only small differences were found among the FTIR spectra of hydrothermally treated samples obtained under different conditions.

\subsection{Effect of the addition of depolymerized lignin fractions on the biodiesel oxidation stability}

The biodiesel oxidation stability time (OXY) was measured prior and after adding the samples of SDL to biodiesel. Table 6 shows the results of the impact of adding the SDL samples to biodiesel on the values obtained from the OXY test. Although data in Table 6 seem to point that, for the same reaction time and BLS content, the biodiesel oxidation stability is higher when adding SDL produced at $325^{\circ} \mathrm{C}$ than when adding those obtained at $250^{\circ} \mathrm{C}$, the ANOVA test does not show a clear trend with any of the experimental factors, probably because of the great variability observed in the replicates at the central point.

In order to correlate the properties of the characterized SDL with the biodiesel oxidation stability, a principal component analysis (PCA) was performed taking into account the intensity of the FTIR bands, the average Mn, the concentration of the GC/MS families, (organized by functional groups) and the Folin-Ciocalteu ( $\mathrm{F}-\mathrm{C})$ phenolic concentration. The scores plot (Fig. 6(a)) shows that the first two principal components explain $90.1 \%$ of the total variance, where temperature is the most influential parameter. Data could be grouped in three clusters corresponding to the three tested temperatures. Fig. 6(b) shows the correlation loadings. Results show that the FTIR bands at 1561 and $1355 \mathrm{~cm}^{-1}$ are moderately related with the OXY increase (correlation 0.665 and 0.510 ), whereas there is a strong correlation between phenolics and ethers (by GC/MS, 0.932) and phenolics (by GC/MS) vs. $\mathrm{F}-\mathrm{C}$ concentration $(0.700)$. Phenolics show moderate correlation with $\mathrm{Mn}(0.582)$ and the IR band at $1446 \mathrm{~cm}^{-1}(0.571)$. The worst agreement $(0.451)$ is found between phenolics and $\mathrm{OXY}$, thus indicating that the improvement in the antioxidant properties is not only due to 
the presence of volatile phenolics, being also significant the compounds present into the non-volatile fraction.

Table 6: OXY improvement of biodiesel after adding the SDL samples.

\begin{tabular}{cccc}
\hline Temp $\left({ }^{\circ} \mathrm{C}\right)$ & $\begin{array}{c}\text { Time } \\
(\mathrm{h})\end{array}$ & BLS content (wt.\%) & $\begin{array}{c}\Delta \mathrm{OXY} \\
(\%)\end{array}$ \\
\hline 250 & 1 & 7 & 19.8 \\
325 & 1 & 7 & 144 \\
250 & 3 & 7 & 31.7 \\
325 & 3 & 7 & 54.8 \\
250 & 1 & 14 & 8.7 \\
325 & 1 & 14 & 33.6 \\
250 & 3 & 14 & 13 \\
325 & 3 & 14 & 24.7 \\
287.5 & 2 & 10.5 & 78.7 \\
287.5 & 2 & 10.5 & 94.7 \\
287.5 & 2 & 10.5 & 83.9 \\
\hline
\end{tabular}

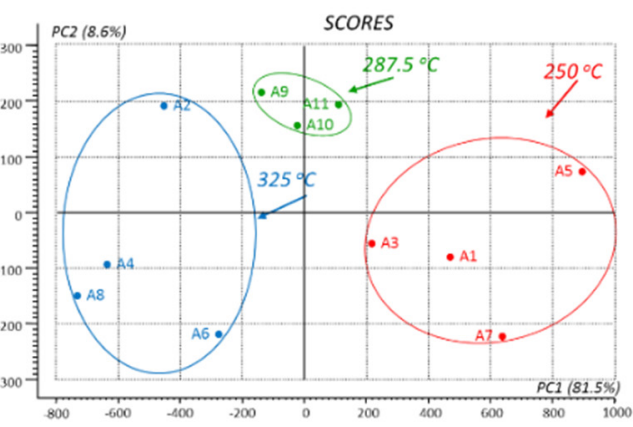

(a)

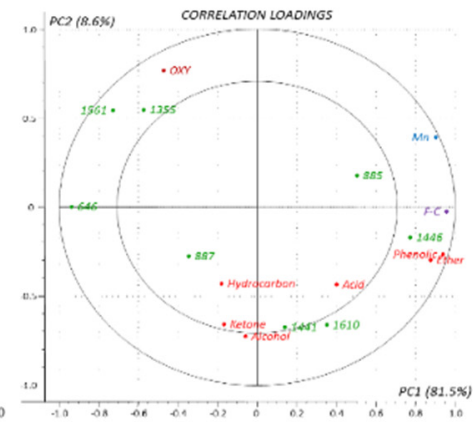

(b)

Figure 6: (a) Scores; and (b) Correlation loadings plots of principal components $1(81.5 \%$ of explained variance) and $2(8.6 \%)$.

\section{CONCLUSIONS}

Black liquor from straw was produced and depolymerized in a batch reactor. The depolymerized lignin was tested as antioxidant for biodiesel. Although the observed increase on the biodiesel oxidation stability was moderate, the results show potential for the valorization of this byproduct of the pulping industry. The depolymerized lignin was characterized by GPC, GC/MS, Folin-Ciocalteu phenolic concentration and FTIR spectroscopy. The effect of the experimental conditions was noticeable on the molecular weight distribution measured by GPC, especially the effect of reaction temperature, which was overall identified as the most influential parameter. The increased temperature decreased the molecular weight, as well as the phenolic content, measured either by GC/MS or with the Folin-Ciocalteu method. FTIR showed the presence of functional groups that can be assigned to phenolic compounds, as aromatic ring, phenolic rings and $\mathrm{OH}$ vibrations. The oxidation stability increase could not be clearly correlated with the analyzed parameters of the depolymerized BL. 


\section{ACKNOWLEDGEMENTS}

The authors acknowledge the funding from the Aragón Government (Ref. T22_17R), co-funded by FEDER 2014-2020 "Construyendo Europa desde Aragón”" and Ministerio de Economía y Competitividad (Gobierno de España) for the project ENE2017-85040-R: Renewable additives for biofuels.

\section{REFERENCES}

[1] Lora, J.H. \& Escudero, E., Soda pulping of agricultural fibres for boardmaking applications. Paper Technol., 41, pp. 37-42, 2000.

[2] Ono, K., Isono, Z. \& Tsuda, T., Desilicification from the high silica containing kraft black liquor by the improved carbon dioxide method. Agric. Biol. Chem., 33, pp. 622624, 1969.

[3] Marín, F. et al., Semichemical pulping of Miscanthus giganteus. Effect of pulping conditions on some pulp and paper properties. Bioresour. Technol., 100, pp. 39333940, 2009.

[4] Gonzalo, A. et al., Evaluation of different agricultural residues as raw materials for pulp and paper production using a semichemical process. J. Clean. Prod., 156, pp. 184-193, 2017.

[5] Mahmood, N. et al., Hydrolytic depolymerization of hydrolysis lignin: Effects of catalysts and solvents. Bioresour. Technol., 2015.

DOI: 10.1016/j.biortech.2015.04.074.

[6] Beauchet, R., Monteil-Rivera, F. \& Lavoie, J.M., Conversion of lignin to aromaticbased chemicals (L-chems) and biofuels (L-fuels). Bioresou.r Technol., 121, pp. 328334, 2012.

[7] García, M. et al., Antioxidants for biodiesel: Additives prepared from extracted fractions of bio-oil. Fuel Process Technol., 156, pp. 407-414, 2017.

[8] Lange, H., Rulli, F. \& Crestini, C., Gel permeation chromatography in determining molecular weights of lignins: Critical aspects revisited for improved utility in the development of novel materials. ACS Sustain. Chem. Eng., 4, pp. 5167-5180, 2016.

[9] Asikkala, J. \& Tamminen, T., Argyropoulos DS: Accurate and reproducible determination of lignin molar mass by acetobromination. J. Agric. Food Chem., 60, pp. 8968-8973, 2012.

[10] Ristolainen, M., Alén, R. \& Knuutinen, J., Characterization of TCF effluents from kraft pulp bleaching. I. Fractionation of hardwood lignin-derived material by GPC and UF. Holzforschung, 50, pp. 91-96, 1996.

[11] Pakkanen, H. \& Alén, R., Molecular mass distribution of lignin from the alkaline pulping of hardwood, softwood, and wheat straw. J. Wood Chem. Technol., 32, pp. 279-293, 2012.

[12] Kissin, Y.V., Molecular weight distributions of linear polymers: Detailed analysis from GPC data. J. Polym. Sci. Part A: Polym. Chem., 33, pp. 227-237, 1995.

[13] Clementi, L.A. et al., Molar mass distributions in homopolymer blends from multimodal chromatograms obtained by $\mathrm{Sec} / \mathrm{Gpc}$ with a concentration detector. Polym. Test, 43, pp. 58-67, 2015.

[14] El Mansouri, N.-E. \& Salvadó, J., Analytical methods for determining functional groups in various technical lignins. Ind. Crops Prods., 26, pp. 116-124, 2007.

[15] Derkacheva, O. \& Sukhov, D., Investigation of lignins by FTIR spectroscopy. Macromol. Symp., 265, pp. 61-68, 2008. 